\title{
Symmetrical Serotonin Release during Asymmetrical Slow-Wave Sleep: Implications for the Neurochemistry of Sleep-Waking States
}

\author{
Jennifer L. Lapierre, ${ }^{1,2,3}$ Peter 0. Kosenko, ${ }^{4,5}$ Tohru Kodama, ${ }^{6}$ John H. Peever, ${ }^{3}$ Lev M. Mukhametov, ${ }^{4}$ Oleg I. Lyamin, ${ }^{1,2,4}$ \\ and Jerome M. Siegel ${ }^{1,2}$ \\ ${ }^{1}$ Department of Psychiatry and Biobehavioral Sciences, and Brain Research Institute, University of California Los Angeles, Los Angeles, California 90024, \\ ${ }^{2}$ Neurobiology Research, Veterans Affairs Greater Los Angeles Healthcare System, North Hills, California 91343, ${ }^{3}$ Department of Cell and Systems Biology, \\ University of Toronto, Toronto, Ontario, Canada M5S-3G5, ${ }^{4}$ Utrish Dolphinarium Limited, Moscow, Russia, 119040, ${ }^{5}$ Department of General Biology, \\ Southern Federal University, Rostov-on-Don, Russia, 344006, and ${ }^{6}$ Department of Dementia and Higher Brain Function, Tokyo Metropolitan Institute of \\ Medical Science, Tokyo, Japan 156-8506
}

On land, fur seals predominately display bilaterally synchronized electroencephalogram (EEG) activity during slow-wave sleep (SWS), similar to that observed in all terrestrial mammals. In water, however, fur seals exhibit asymmetric slow-wave sleep (ASWS), resembling the unihemispheric slow-wave sleep of odontocetes (toothed whales). The unique sleeping pattern of fur seals allows us to distinguish neuronal mechanisms mediating EEG changes from those mediating behavioral quiescence. In a prior study we found that cortical acetylcholine release is lateralized during ASWS in the northern fur seal, with greater release in the hemisphere displaying low-voltage (waking) EEG activity, linking acetylcholine release to hemispheric EEG activation (Lapierre et al. 2007). In contrast to acetylcholine, we now report that cortical serotonin release is not lateralized during ASWS. Our data demonstrate that bilaterally symmetric levels of serotonin are compatible with interhemispheric EEG asymmetry in the fur seal. We also find greatly elevated levels during eating and hosing the animals with water, suggesting that serotonin is more closely linked to bilateral variables, such as axial motor and autonomic control, than to the lateralized cortical activation manifested in asymmetrical sleep.

\section{Introduction}

On land, fur seals (Callorhinus ursinus) predominately display symmetrical bihemispheric slow-wave sleep (BSWS), similar to that observed in terrestrial mammals. In water, however, interhemispheric electroencephalographic (EEG) asymmetry is seen during slow-wave sleep (SWS) (Lyamin and Mukhametov, 1998), resembling the unihemispheric slow-waves of odontocetes (toothed whales) (Lyamin et al., 2008b). During this state, named asymmetrical SWS (ASWS), one hemisphere displays a highvoltage, low-frequency EEG (slow-wave activity, SWA), while the other exhibits a lower voltage waking EEG. In water, the posture mirrors this asymmetrical EEG, with the foreflipper contralateral to the activated hemisphere moving to maintain the seal's body

\footnotetext{
Received May 30, 2012; revised Nov. 19, 2012; accepted Dec. 12, 2012.

Author contributions: J.L.L., L.M.M., 0.I.L., and J.M.S. designed research; J.L.L., P.O.K., T.K., O.I.L., and J.M.S. performed research; L.M.M. contributed unpublished reagents/analytic tools; J.L.L., P.O.K., T.K., J.H.P., 0.I.L., and J.M.S. analyzed data; J.L.L., J.H.P., 0.I.L., and J.M.S. wrote the paper.

This work was supported by National Institutes of Health Grant R01-NS069640, National Science Foundation Grant 0919929, Medical Research Service of the Department of Veterans Affairs, Utrish Dolphinarium, National Science and Engineering Council of Canada, and Canadian Institutes of Health Research. We thank S. Azuma for technical support, I. Pavlova and S. Korneva for laboratory assistance, R. McGregor for help with figure preparation, and personnel of the Utrish Marine Station for veterinary and animal care.

The authors declare no competing financial interests.

Correspondence should be addressed to Dr. Jerome M. Siegel, Neurobiology Research (151-A3), 16111 Plummer Street, North Hills, CA 91343. E-mail: jsiegel@ucla.edu.

DOI:10.1523/JNEUROSCI.2603-12.2013

Copyright $\odot 2013$ the authors $\quad 0270-6474 / 13 / 332555-07 \$ 15.00 / 0$
}

orientation at the surface and the contralateral eye briefly opening, while the other foreflipper and eye remains immobile and closed, respectively. ASWS sleep is thought to enable monitoring of the environment for predators, to facilitate respiration without aspiration of water, to conserve energy via postural thermogenesis (Lyamin et al., 2008b), and to reduce hemispheric brain metabolism (Siegel, 2009).

Our knowledge pertaining to the neurotransmitters involved in sleep-wake regulation has been derived from species that display bilaterally symmetrical EEG states, particularly cats, rats, and mice. However, such studies do not indicate which aspects of sleep these neurotransmitters are linked to. The unique sleeping pattern of fur seals, however, allows us to dissociate the neuronal mechanisms mediating the cortical EEG activity of sleep from those mediating sleep's behavioral quiescence, with its associated reductions in heart rate, respiration, movement, muscle tone, and body temperature. Previously we found that cortical acetylcholine release in fur seals (Lapierre et al., 2007) was similar to that in land mammals, with maximal release during waking and minimal release during BSWS (Marrosu et al., 1995). During ASWS, however, cortical acetylcholine release was strongly lateralized, with greater levels in the hemisphere displaying lower voltage EEG activity (Lapierre et al., 2007).

Serotonin-containing neurons, located in the raphe nuclei of the brainstem, project widely throughout the CNS (Andén et al., 1965). In dogs, cats, rodents, and primates, serotonin neurons 
fire maximally during active wakefulness (AW), decrease their discharge rate during quiet wakefulness $(\mathrm{QW})$, further decrease their rate during SWS, and cease firing during rapid eye movement (REM) sleep (McGinty and Harper, 1976; Jacobs and Fornal, 1999). The relation of serotonin activity to arousal suggests that serotonin release, like acetylcholine release, may be asymmetrical during ASWS, with maximal release in the activated hemisphere. Most reports indicate that serotonin neurons project in a predominately ipsilateral fashion to the cortex and other forebrain structures, indicating the possibility of asymmetrical release. However, the tight midline clustering of the somata of serotonin neurons indicates that they may receive common excitatory and inhibitory inputs (Brown et al., 2002). This and the widely branching pattern of axonal projections of serotonin neurons (Jacobs et al., 1978; Van Der Kooy and Hattori, 1980; O'Hearn and Molliver, 1984; Kanno et al., 2008) suggest that serotonin release may be bilaterally symmetrical. In the present study we measured serotonin release bilaterally during both BSWS and ASWS to determine the actual pattern of release in the fur seal.

\section{Materials and Methods}

Animals. All procedures were approved by the University of California Los Angeles and the Veterans Affairs Greater Los Angeles Healthcare System Committees. All studies were conducted in accordance with the National Institute of Health Guide for the Care and Use of Experimental Animals. Experiments were performed at the Utrish Marine Station (a facility of the Severtsov Institute of Ecology and Evolution of the Russian Academy of Sciences) on the Black Sea, Russia. Data were collected from four juvenile northern fur seals (one male and three females, $20-21 \mathrm{~kg}$, 2-3 years old). Fur seals were captured on the Commander Islands, Russia, located in the Western Pacific, 1 year before the study and were well adapted to captivity. Three days before surgery, each fur seal to be studied was moved to an empty indoor laboratory pool and placed into the microdialysis recording chamber $(1.1 \times 0.8 \times 0.8 \mathrm{~m})$ for $4-6 \mathrm{~h}$ each day. Fur seals were fed fish twice per day (between 8:00 and 9:00 and 17:00 and 18:00) and sprayed with water for 10-20 min after each feeding, following standard pinniped husbandry procedures. During the daytime (8: 00-20:00), the enclosure was illuminated by artificial light (400-500 lux at floor level); at night the level of illumination was reduced to $\leq 50$ lux. Room temperature during recording ranged from $15^{\circ}-25^{\circ} \mathrm{C}$.

Surgical procedures. All surgical procedures have been previously described in detail (Lapierre et al. 2007). Briefly, in addition to EEG, electromyogram (EMG), and electrooculogram electrodes, two or four pairs of guide cannulas sealed with stylets (CMA 12 Guide Cannula; CMA Microdialysis) were implanted in symmetrical locations in each hemisphere (Fig. 1). Following the implantation procedure, the animal was returned to the indoor enclosure and allowed a minimum of 1 week to recover.

Microdialysis procedure. On the morning of the experiment, the fur seal was anesthetized with isoflurane as described previously (Lapierre et al. 2007), and the stylets were replaced with microdialysis probes. Probes had a 4-mm-long semi-permeable polyarylethersulfone membrane $(0.5$ mm diameter, $20 \mathrm{kDa}$ cutoff; CMA-12 Elite Microdialysis Probe; CMA Microdialysis). Shielded Teflon tubing (1.5 m, TJT-10-150HS; Eicom) encased within an additional protective sleeve was connected to the inlet and outlet of each probe. After the implantation procedure, which lasted about $1.5 \mathrm{~h}$, the seal was placed in the recording chamber where it remained unrestrained for the duration of the experiment. Subsequently, the tubing from each probe inlet was connected to a syringe pump (ESP64; Eicom) and the microdialysis probe was perfused with aCSF (Perfusion Fluid CNS containing $147 \mathrm{~mm} \mathrm{NaCl}, 2.7 \mathrm{~mm} \mathrm{KCl}, 1.2 \mathrm{~mm} \mathrm{CaCl}_{2}$, and $0.85 \mathrm{mM} \mathrm{MgCl}_{2} ; \mathrm{CMA}$ Microdialysis) at a rate of $1.5 \mu \mathrm{l} / \mathrm{min}$. The tubing from each probe outlet was connected to a fraction collector (EFC-82; Eicom). After a minimum $4 \mathrm{~h}$ stabilization period, samples were collected every $10 \mathrm{~min}$ over the course of $40 \mathrm{~h}$, on average. Before sample collection, $7.5 \mu \mathrm{l}$ of anti-oxidant solution $(20 \mu \mathrm{M}$ cysteine in $20 \mathrm{~mm}$ phosphate buffer, $\mathrm{pH} 3.5$, containing $200 \mu \mathrm{M}$ EDTA-2Na) was added to each sample vial. During collection, samples $(22.5 \mu \mathrm{l})$ were kept at $4^{\circ} \mathrm{C}$ (EFR-82 Cooling Unit; Eicom) and each hour they were transferred to a $-80^{\circ} \mathrm{C}$ freezer and stored until analyzed.

Assay of serotonin. Samples were assayed for serotonin (5hydroxytryptamine, 5-HT) using high-performance liquid chromatography (HPLC) coupled with electrochemical detection (HTEC-500; Eicom). Samples maintained at $4^{\circ} \mathrm{C}$ were injected into the HPLC system using an autosampler (832 Temperature Regulator, 402 Syringe Pump, 231 XL Sample Injector; Gilson). The mobile phase, consisting of $0.1 \mathrm{M}$ phosphate buffer ( $\mathrm{pH}$ 6.0) containing sodium-1-decanesulfonate $(500$ mg/L; Tokyo Kasei Kogyo), EDTA-2Na (50 mg/L; Dojindo Laboratories), and $1 \%$ methanol, was filtered through a guard (pre) column (PC-04 with AC-ODS or CA-ODS packing material; Eicom) and delivered at a rate of $500 \mu \mathrm{l} / \mathrm{min}$. An inline filter (PP-LF; Eicom) was placed before the separation column. Serotonin was separated on a reversedphased column (Eicompak PP-ODS column; Eicom) maintained at $25^{\circ} \mathrm{C}$. The amount of serotonin was electrochemically detected by a graphite working electrode (WE-3G; Eicom) set to $+400 \mathrm{mV}$ against an $\mathrm{Ag} / \mathrm{AgCl}$ reference electrode (RE-500; Eicom). The signal from the detector was recorded using a data acquisition system (EPC-300; Eicom) and analyzed using PowerChrom software (eDAQ). Before each experiment, the HPLC system was tested for linearity and sensitivity using 10 concentrations of serotonin ranging from $45 \mathrm{fg}$ (detection limit for serotonin with a 3:1 signal-to-noise ratio) to $18 \mathrm{pg}$ per injection (18 $\mu \mathrm{l})$. Every $8 \mathrm{~h}$ during sample analysis, the HPLC system was calibrated using an external standard containing a known concentration of serotonin. Quantification of serotonin in each dialysate was determined by comparing the sample peak height to the calibration curve generated from the serotonin standards.

Electroencephalogram recording and analysis. Electrophysiological parameters were recorded and analyzed as described previously (Lapierre et al. 2007; Lyamin et al. 2008a). For each hemisphere, EEG was visually scored in $20 \mathrm{~s}$ epochs as follows: (1) desynchronization (low-amplitude, high-frequency; stage 1 EEG); (2) low-amplitude synchronization (sleep spindles and slow waves $(0.5-4.0 \mathrm{~Hz})$, which exceeded stage 1 amplitude by at least 1.5 times and with waves of maximal amplitude occupying $<50 \%$ of the epoch; stage 2 EEG); or (3) high amplitude synchronization (slow waves of maximal amplitude occupying $>50 \%$ of the epoch; stage 3 EEG). Waking was characterized by stage 1 EEG in both hemispheres combined with sustained muscle tone and/or bursts of muscle activity. AW was scored when the animal was moving around the recording cage or grooming. Two additional active behaviors were analyzed separately: AW-feed when the seal was being fed and AW-hose when the animal was being hosed down with water. Seals typically approached the hose and appeared to enjoy this activity. QW was scored when the seal was laying or sitting either motionless or with occasional shifts in body position during which time their eyes could be open or closed. REM sleep was scored when a desynchronized EEG typical of waking (i.e., stage 1 EEG) in both hemispheres was accompanied by a significant reduction in EMG tone or full atonia, muscle jerks, facial twitches, and rapid eye movements. BSWS was scored when stage 2 and/or stage 3 EEG appeared simultaneously in both hemispheres along with lower or similar amplitude EMG activity as seen during QW. Although fur seals preferentially sleep bihemispherically on land (i.e., in the recording chamber), some animals exhibit a substantial amount of ASWS as well (Lyamin and Mukhametov, 1998; Lyamin et al. 2008a). ASWS on land is often accompanied by brief opening of the contralateral eye while the other eye remains closed (Lyamin et al., 2004); however, it is not accompanied by the motor asymmetry observed in water but rather the posture is similar during BSWS and ASWS, with the animal typically lying on the cage floor with little to no movement. Left or right ASWS (LASWS or RASWS) was scored when stage 3 EEG occurred in the one hemisphere and stage 2 or stage 1 EEG occurred in the other hemisphere or when stage 2 EEG occurred in the one hemisphere and stage 1 EEG occurred in the other hemisphere. The percentage of time spent in each behavioral state was calculated for each sample. Dialysates were classified as AW-hose, AWfeed, AW, QW, BSWS, or REM sleep samples when a single behavioral state occupied $75 \%$ or more of the sampling interval. When SWS occu- 


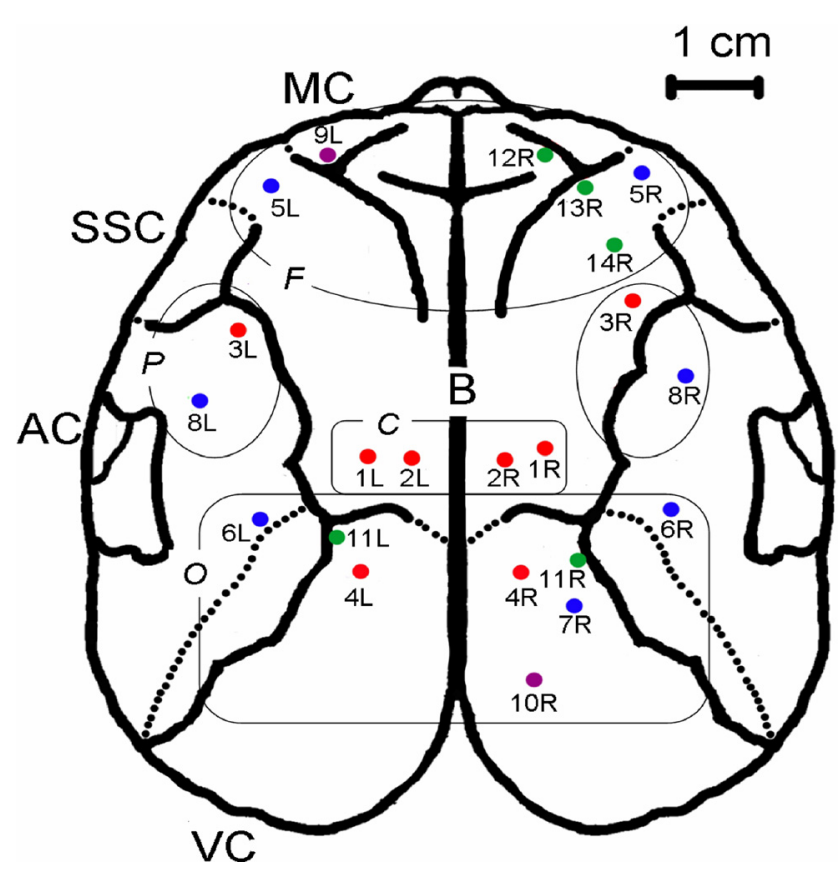

Figure 1. Reconstructed schematic illustrating the localization of microdialysis probes ( $n=$ 22) in the cerebral cortex. Dotted outlines demark main cortical areas: motor cortex (MC), auditory cortex (AC), somatosensory cortex (SSC), and visual cortex (VC) and were taken from Supin et al. (2001) with the permission of Kluwer Academic. Microdialysis probes were grouped within four broad regions: frontal $(F)$, parietal $(P)$, central $(C)$, and occipital $(0)$. Each color represents an individual fur seal.

pied $\geq 75 \%$ of the sampling interval but $<25 \%$ of it was BSWS, the sample was classified as either LASWS or RASWS. All remaining samples were classified as a mixed state.

Histological analysis. Probe placement within the cortex was verified following procedures reported previously by Lapierre et al. 2007.

Statistical analysis. All statistical analyses were performed using GraphPad Prism version 5.00 for Windows (GraphPad Software). Data were assessed for statistical significance using either one-way ANOVA with repeated-measures followed by Tukey's post hoc multiple-comparison tests, paired $t$ test, or Pearson's correlation coefficient. Values are given as mean \pm SEM.

\section{Results}

\section{Localization of cortical microdialysis probes}

Fourteen pairs of guide cannulas were implanted in symmetrical locations within each hemisphere in a total of four fur seals; however, due to technical difficulties samples were analyzed from 9 and 13 probes in the left and right hemispheres, respectively. One thousand eight hundred and seventy-eight samples met the criteria described in the Materials and Methods. Sixty-eight active waking periods when the seal was being sprayed with water were identified (AW-hose), 78 feeding (AW-feed), 428 AW, 870 QW, 145 BSWS, 121 LASWS, 152 RASWS, and 16 REM sleep. Microdialysis probes were located within four cortical areas: frontal $(n=6)$, parietal $(n=4)$, central $(n=4)$, and occipital $(n=8)$ (Fig. 1$)$. Mean serotonin release was not significantly different between cortical areas $\left(F_{(3,7)}=1.692, p=0.1993\right)$.

\section{Cortical serotonin release varies with behavioral state}

Representative chromatograms of serotonin peaks obtained from samples collected across the sleep-wake cycle are illustrated in Figure 2. The animals were studied during BSWS and ASWS periods occurring in the dry recording chamber. Mean cortical

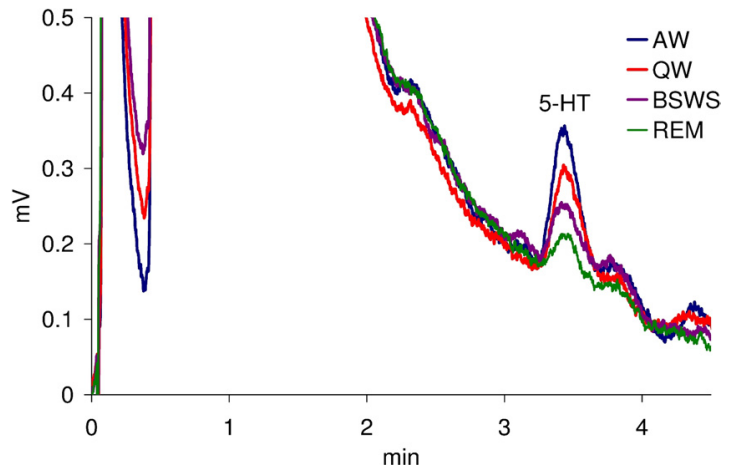

Figure 2. Typical chromatograms displaying the level of serotonin (5-HT) in dialysates collected from the central cortical region (probe $2 \mathrm{~L}$ in Fig. 2) during bilaterally symmetrical EEG states-active waking (AW), quiet waking (QW), bilateral slow-wave sleep (BSWS), and rapid eye movement sleep (REM). Serotonin eluted at a retention time of $\sim 3.5 \mathrm{~min}$.

serotonin release was state-dependent $\left(F_{(5,10)}=23.26 ; p<\right.$ 0.0001 ); serotonin release was maximal during AW and minimal during REM sleep. Post hoc tests indicated that mean cortical serotonin release was significantly higher during AW when compared to BSWS $(p<0.001)$ and REM sleep $(p<$ $0.001)$, significantly higher during QW when compared to BSWS $(p<0.01)$ and REM sleep $(p<0.001)$, and significantly higher during BSWS when compared to REM sleep $(p<0.05)$. Serotonin levels were $264 \pm 4.9 \mathrm{fg} / 18 \mu \mathrm{l}$ sample during AW, $213 \pm$ $4.0 \mathrm{fg} / 18 \mu \mathrm{l}$ sample during QW, $158 \pm 4.6 \mathrm{fg} / 18 \mu \mathrm{l}$ sample during BSWS, and $108 \pm 4.5 \mathrm{fg} / 18 \mu \mathrm{l}$ sample during REM sleep. Serotonin levels were at $125 \%$ of QW levels during AW, $74 \%$ during BSWS, and 51\% during REM sleep (Fig. $3 A, B$ ).

\section{Cortical serotonin release is not lateralized during ASWS}

EEG power in the $\delta$ frequency range $(1.2-4 \mathrm{~Hz}$; i.e., SWA) was maximally expressed in both hemispheres during BSWS and minimally expressed during QW and REM sleep (Fig. 3A). Average SWA did not differ between hemispheres during BSWS $\left(t_{(5)}\right.$ $=1.782, p=0.1349)$. During LASWS, EEG power $(1.2-4 \mathrm{~Hz})$ was significantly higher in the left hemisphere compared to that in the right hemisphere $\left(t_{(6)}=2.638, p<0.05\right)$. The opposite was observed during RASWS, with SWA being significantly higher in the right hemisphere $\left(t_{(8)}=3.450, p<0.01\right)$. The average asymmetry index (Lyamin et al. 2008a) was $-0.046 \pm 0.028$ during BSWS, $0.573 \pm 0.037$ during LASWS, and $-0.596 \pm 0.047$ during RASWS.

During ASWS, mean serotonin release in the ipsilateral and contralateral hemispheres were not significantly different $\left(t_{(19)}=0.7955, p=0.4361\right)$; that is to say, serotonin release was not lateralized during ASWS (Fig. 3B). Post hoc tests showed that mean cortical serotonin release was significantly higher during AW when compared to LASWS $(p<0.001)$ and RASWS $(p<0.001)$ and significantly lower during REM sleep when compared to LASWS $(p<0.001)$ and RASWS $(p<$ $0.01)$. Cortical serotonin release during LASWS and RASWS was similar to that observed during both QW and BSWS. Serotonin levels were $185 \pm 3.9 \mathrm{fg} / 18 \mu \mathrm{l}$ sample during LASWS and $182 \pm 3.0 \mathrm{fg} / 18 \mu \mathrm{l}$ sample during RASWS. When compared to QW, serotonin levels were at 89\% during LASWS and $85 \%$ during RASWS. 

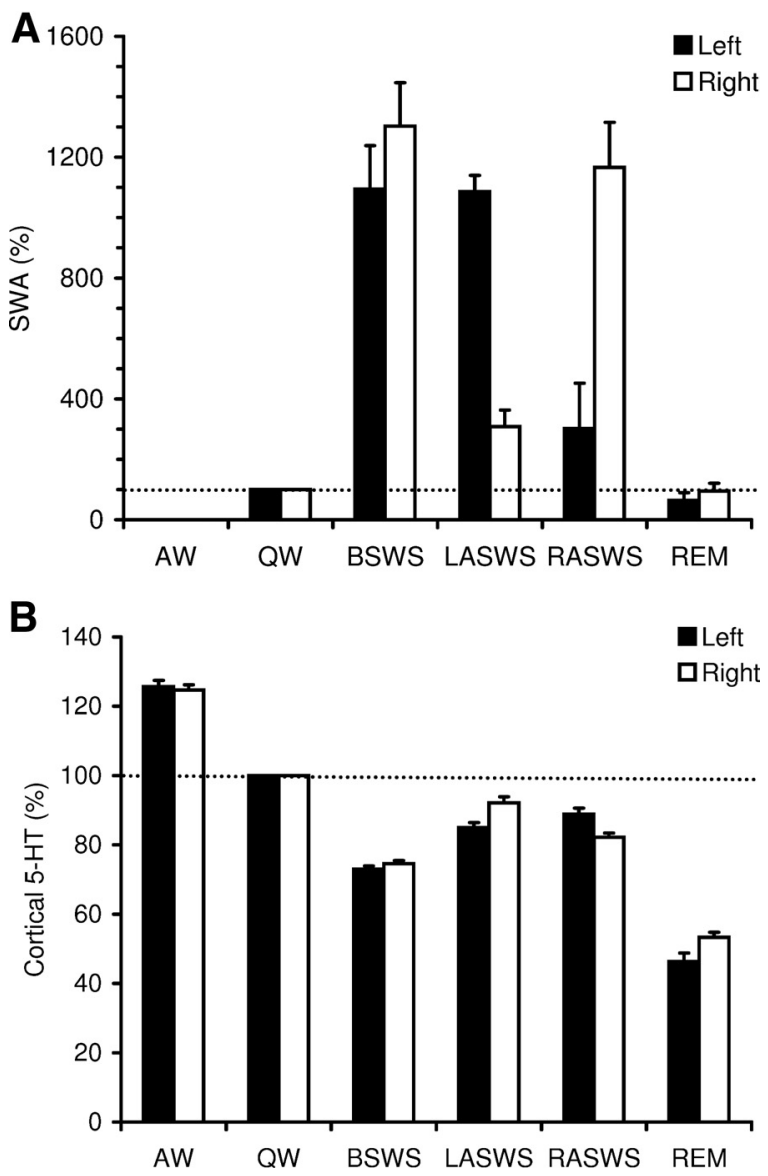

Figure 3. $A$, EEG power in the $\delta$ frequency range (1.2-4 Hz; SWA) across the sleepwake cycle - active waking (AW), quiet waking (QW), bilateral slow wave sleep (BSWS), left asymmetrical slow wave sleep (LASWS), right asymmetrical slow wave sleep (RASWS), and rapid eye movement (REM) sleep. Each column represents the mean + SEM of the percent change in SWA relative to quiet waking. $\boldsymbol{B}$, Cortical $5-\mathrm{HT}$ release across the sleep-wake cycle. Each column represent the mean + SEM of the percent change in 5-HT levels relative to $\mathrm{QW}$ for 9 and 13 probes in the left and right hemispheres, respectively.

\section{Cortical serotonin release is elevated during certain waking states}

The nature of waking behavior had a significant effect on mean cortical serotonin release $\left(F_{(3,16)}=15.46, p<0.0001\right)$. Post hoc tests revealed that hosing down the animals with water significantly elevated serotonin release when compared to the other three waking behaviors (in each case, $p<0.001$; all other comparisons were not significant). Cortical serotonin release was $743 \pm 31.3 \mathrm{fg} / 18 \mu \mathrm{l}$ sample during AW-hose and $363 \pm 10.5 \mathrm{fg} / 18$ $\mu l$ sample during AW-feed. Cortical serotonin levels were at $420 \%$ of QW levels during AW-hose and 171\% during AW-feed (Fig. 4).

\section{Cortical serotonin release differs from cortical acetylcholine release during ASWS}

Here we compare cortical serotonin release from the present study with cortical acetylcholine results obtained in an earlier study on a separate group of fur seals (Lapierre et al. 2007). During ASWS, cortical acetylcholine levels in the ipsilateral hemisphere (displaying slow waves) were similar to those observed during BSWS, whereas levels in the contralateral (activated) hemisphere were comparable to those observed during QW (Lapierre et al., 2007). During ASWS, the pattern of cortical serotonin release clearly differed from that of acetylcholine release

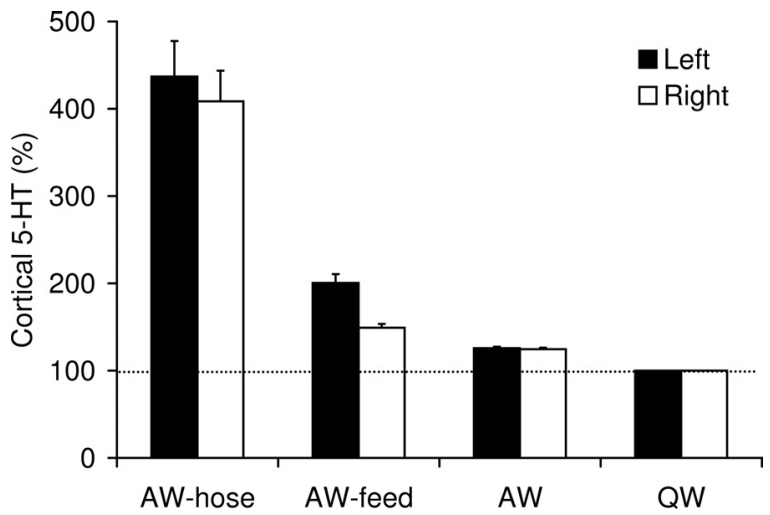

Figure 4. Cortical serotonin (5-HT) release during various waking states - hosing down with water (AW-hose), feeding (AW-feed), active waking (AW), and quiet waking (QW). Each column represents the mean + SEM of the percent change in serotonin levels relative to $\mathrm{QW}$ for 9 and 13 probes in the left and right hemispheres, respectively.

observed under the same conditions. Serotonin was symmetrically released in both hemispheres during ASWS (Fig. 5). In addition, EEG power $(1.2-4 \mathrm{~Hz})$ and cortical acetylcholine release in the same hemisphere were negatively correlated (Lapierre et al., 2007); however, there was no correlation between SWA and cortical serotonin release during ASWS ( $p$ ranged from 0.095 to 0.939 for all comparisons).

\section{Discussion}

\section{Serotonin and sleep}

Early evidence suggested a role for serotonin in sleep induction and maintenance. Lesion of the dorsal raphe produces a profound insomnia in cats. Depletion of serotonin with p-chlorophenylalanine (PCPA) also produces insomnia (Jouvet, 1969; Ursin et al., 1989). This insomnia is reversed by administration of the serotonin precursor 5-hydroxytryptophan, 5-HTP (Puizillout et al., 1981). Application of serotonin to thalamic nuclei increases local slow-wave occurrence (Rinaldi et al., 1975). Studies using brain slices have indicated that the release of serotonin during waking may have a role in the subsequent activation of sleep-active neurons in the preoptic area (Jouvet, 1999). These findings led to the serotonergic hypothesis of SWS generation in which an elevated serotonin level was linked to and required for SWS (Jouvet, 1999). However, some further work cast doubt on this hypothesis. Administration of PCPA in humans and rats does not produce insomnia (Wyatt et al., 1969; Ross et al., 1976). Administration of serotonin receptor agonists and uptake inhibitors increases wakefulness rather than sleep in the rat (Ursin et al., 1989; Monti, 2011). The hypothesis of a direct role for serotonin release in sleep induction was further undermined by the finding that all serotonergic neurons are maximally active in waking with a considerable reduction in rate during SWS (McGinty and Harper, 1976). Therefore, this presents a reverse of the profile initially predicted from the depletion studies and suggests that serotonin depletion produces insomnia though nonspecific effects. Nevertheless, health food stores throughout the world continue to sell tryptophan as a sleep aid (a Google search for "serotonin sleep" brings up 6,900,000 hits), and it continues to be mentioned in the scientific literature as a sleep-related substance.

In an extensive series of studies in cats and rats, Jacobs and his collaborators studied the unit activity of the serotonergic cell groups as well as serotonin release across the sleep-wake cycle and under a variety of behavioral and physiological conditions in unrestrained animals. They found that all such cells were maxi- 


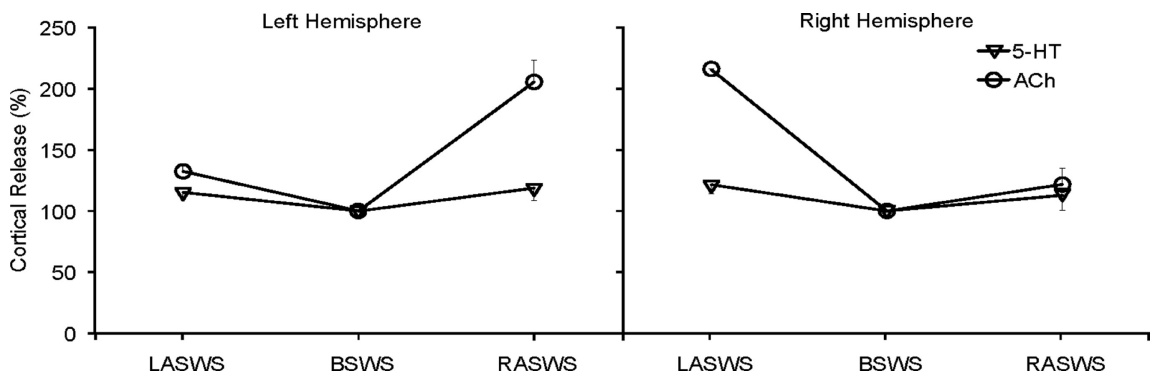

Figure 5. Cortical serotonin (5-HT) and acetylcholine (ACh) release during slow-wave sleep (SWS) — bilateral SWS (BSWS), left asymmetrical SWS (LASWS), and right asymmetrical SWS (RASWS). 5-HT release was symmetrical during ASWS, whereas ACh release was highly lateralized. Each point represents the mean \pm SEM of the percent change in neurotransmitter level relative to BSWS. 5-HT data shown here were obtained from 6 and 8 probes in the left and right hemisphere, respectively. ACh data shown were taken from our prior study (Lapierre et al. 2007) and were obtained from 4 probes in both the left and right hemisphere.

mally active during motor activity (Jacobs and Fornal, 1999), with medullary raphe cells highly activated by treadmill locomotion (Jacobs et al., 2002), whereas cells in the dorsal raphe nucleus, the most rostrally located brainstem serotonergic group, were maximally active during the rhythmic mouth movement of feeding and in association with respiration (Fornal et al., 1996; Veasey et al., 1997). In contrast, it was found that stressors did not activate these cells beyond normal active waking levels (Jacobs et al., 1990). Manipulation of blood pressure and baroreceptor stimulation did not affect serotonin neuronal activity (MartinCora et al., 2005), and neither did thermoregulatory challenges, alterations in blood glucose, or elevations of endogenous circulating insulin (Fornal et al., 1989). Thus, these studies concluded that increased activity of serotonergic cells in waking is linked to rhythmic axial motor activity.

REM sleep without atonia, produced by pontine lesion, eliminates the muscle tone suppression characteristic of REM sleep without greatly interfering with its other aspects. The REM sleep without atonia syndrome is accompanied by greatly increased raphe unit activity during REM sleep (Jacobs and Fornal, 1999). REM sleep without atonia is believed to be similar to the REM sleep behavior disorder in humans in which patients act out their dreams (Mahowald and Schenck, 2005). The results of the current study are consistent with these findings in showing that reduced cortical serotonin release is correlated with generalized reduction of axial muscle tone present in QW and SWS, regardless of hemispheric EEG asymmetry.

Serotonin has been shown to have a role in restricting pontogeniculo-occipital (PGO) spikes, EEG waves closely linked to rapid eye movements and autonomic changes, to REM sleep. Lesion of serotonergic neurons or depletion of serotonin leads to a release of these waves into all phases of sleep and waking (Simon et al., 1973), suggesting that release of such events may underlie the insomnia produced by depletion of serotonin in cats, a species in which PGO activity is prominent. In the current study, we see the lowest level of serotonin release during REM sleep, when phasic events, including rapid eye movements (Lyamin et al., 2008a), occur in fur seals, as in their phylogenetically related carnivore, the cat.

\section{Serotonin and EEG}

Although serotonin release is reduced in BSWS, it is significantly lower in REM sleep, a state of EEG activation. This is in contrast to cortical acetylcholine release, which is elevated in both waking and REM sleep, in parallel with EEG changes (Marrosu et al.
1995; Lapierre et al. 2007). The current work demonstrates, for the first time, that EEG synchrony can be present in one cortical hemisphere with quiet waking levels of serotonin release, as observed in the synchronized hemisphere during ASWS. It remains to be determined whether other "REM-off" cells groups, specifically the histamine, norepinephrine, and hypocretin cells groups, all implicated in waking function, show a similar lack of cortical lateralization during ASWS. In our previous work we have shown that noradrenergic cells in narcoleptic dogs completely cease firing during cataplexy (Wu et al., 1999), a state of muscle tone suppression with activated EEG, suggesting a role for these cells in maintenance of muscle tone rather than in maintaining a waking EEG, which persists in cataplexy. Similarly, mesopontine reticular cells, likely using glutamate as a transmitter, are active during waking but silent during cataplexy (Siegel et al., 1991; John et al., 2004). Dorsal raphe serotonergic cells reduce firing during cataplexy to levels comparable to those seen in SWS (John et al., 2004; Wu et al., 2004), indicating that they are related to waking behavior or muscle tone in these animals, rather than waking EEG, consistent with the current findings.

\section{Serotonin in humans}

Selective serotonin reuptake inhibitors (SSRIs) have been reported to elevate mood, suggesting that serotonin level is proportional to positive affect. However, this evidence is indirect, with no clear data showing elevated serotonin levels in those with a positive mood or reduced serotonin levels in those with a depressed mood. Furthermore, although the elevation of serotonin levels by SSRIs is immediate, the effect on mood when present has been reported to be delayed by several weeks (Bunney and Bunney, 2012). This suggests that any effect of SSRIs may be indirect, resulting from relatively slow neurological changes rather than being linked to the immediate changes in serotonin level. Some recent work has concluded that the mood-elevating effects of SSRIs is no greater than those of a placebo (Kirsch, 2009; Pigott et al., 2010). Considering the above, the elevated serotonin release that we see when the animal is hosed down relative to other waking conditions can be interpreted as linked to either the increased motor activity manifested in their approach to the hose or the affect linked to this approach. The work by Jacobs and colleagues reviewed above suggests that variables linked to locomotion, rather than affect, are the principal determinants of activity in serotonin cells in carnivores.

\section{Species differences and ASWS}

Dolphins and other toothed cetaceans exhibit only unihemispheric slow-wave activity. They never show the bilateral EEG synchrony characteristic of land mammals. The corpus callosum of cetaceans is greatly reduced in comparison to brain size relative to its size in humans, rodents, and all other placental mammals (Tarpley and Ridgway, 1994). The posterior commissure is greatly enlarged in cetaceans, demonstrating that considerable bilateral communication is possible (Lyamin et al., 2008b). However, the corpus callosum of the fur seal appears comparable in relative size to that of the dog (J.M.S., 
personal observation), to which the fur seal is closely related. Furthermore phocid seals, a family that does not show ASWS, have corpus callosums that appear grossly similar in size to that of otariids and dogs (Lyamin et al., 2008b). Thus the size of the corpus callosum cannot explain the phenomenon of ASWS, whereas the asymmetric release of acetylcholine can. A more detailed analysis of the nature of commissural connections and of the lateralization of projections of putative arousal mediating neurons in the fur seal in comparison to that of other mammals is warranted.

Sleep is defined by a loss of consciousness and responsiveness. It has long been known that the EEG is activated in REM sleep. One explanation for the similar loss of consciousness in SWS and REM sleep is the reduction of activity of "sleep off" monoaminergic and other cell groups in SWS and their even greater reduction in REM sleep. We have previously reported that fur seals switch from their bihemispheric sleeping pattern seen on land to unihemispheric sleep when they are in water. We have further found that REM sleep is greatly reduced when they are in the water (Lyamin et al., 1996). Since in the wild northern fur seals spend the vast majority of their lifespan continuously in water (Kenyon and Wilke, 1953; Gentry, 1997), the current results suggest that, in contrast to the situation of all previously examined land mammals, serotonin neurons may be nearly continuously active for months without any "off period" resembling those seen in REM sleep. This would challenge prior proposals that the cessation of activity in serotonergic neurons is necessary to allow upregulation of their receptors (Hartmann, 1970; Siegel and Rogawski, 1988). Alternatively, the pattern we have seen here over a period of several days in the laboratory may not be duplicated during long periods in the wild, or fur seals may have evolved a mechanism to allow prolonged activity of serotonin neurons without degradation of the function of serotonin or of other neurological systems. In conclusion, our data indicate that either serotonin reduction to sleep levels is not an essential component of sleep in mammals, or ASWS is not simply a lateralized sleep state but a neurochemically unique state differing from the sleep and waking states of other mammals studied to date.

\section{References}

Andén NE, Dahlström A, Fuxe K, Larsson K (1965) Mapping out of catecholamine and 5-hydroxytryptamine neurons innervating the telencephalon and diencephalon. Life Sci 4:1275-1279. CrossRef Medline

Brown RE, Sergeeva OA, Eriksson KS, Haas HL (2002) Convergent excitation of dorsal raphe serotonin neurons by multiple arousal systems (orexin/hypocretin, histamine and noradrenaline). J Neurosci 22:88508859. Medline

Bunney BG, Bunney WE (2012) Rapid-acting antidepressant strategies: mechanisms of action. Int J Neuropsychopharmacol 15:695-713. CrossRef Medline

Fornal CA, Litto WJ, Morilak DA, Jacobs BL (1989) Single-unit responses of serotonergic neurons to glucose and insulin administration in behaving cats. Am J Physiol 257:R1345-R1353. Medline

Fornal CA, Metzler CW, Marrosu F, Ribiero-do-Valle LE, Jacobs BL (1996) A subgroup of dorsal serotonergic neurons in the cat is strongly activated during oral-buccal movements. Brain Res 716:123-133. CrossRef Medline

Gentry RL (1997) Behavioral ecology of the northern fur seal. Princeton, NJ: Princeton UP.

Hartmann E (1970) The D-state and norepinephrine-dependent systems. Intl Psychiatr Clin 7:308-328. Medline

Jacobs BL, Fornal CA (1999) Activity of serotonergic neurons in behaving animals. Neuropsychopharmacology 21:9S-15S. CrossRef Medline

Jacobs BL, Foote SL, Bloom FE (1978) Differential projections of neurons within the dorsal raphe nucleus of the rat: a horseradish peroxidase (HRP) study. Brain Research 147:149-153. CrossRef Medline

Jacobs BL, Wilkinson LO, Fornal CA (1990) The role of brain serotonin: a neurophysiologic perspective. Neuropsychopharmacology 3:473-479. Medline

Jacobs BL, Martín-Cora FJ, Fornal CA (2002) Activity of medullary serotonergic neurons in freely moving animals. Brain Res Rev 40:45-52. CrossRef Medline

John J, Wu MF, Boehmer LN, Siegel JM (2004) Cataplexy-active neurons in the posterior hypothalamus: implications for the role of histamine in sleep and waking behavior. Neuron 42:619-634. CrossRef Medline

Jouvet M (1969) Biogenic amines and the states of sleep. Science 163:32-41. CrossRef Medline

Jouvet M (1999) Sleep and serotonin: an unfinished story. Neuropsychopharmacology 21:24S-27S. CrossRef Medline

Kanno K, Shima S, Ishida Y, Yamanouchi K (2008) Ipsilateral and contralateral serotonergic projections from dorsal and median raphe nuclei to the forebrain in rats: immunofluorescence quantitative analysis. Neurosci Res 61:207-218. CrossRef Medline

Kenyon KW, Wilke F (1953) Migration of the northern fur seal, Callorhinus ursinius. J Mammal 34:86-98. CrossRef

Kirsch I (2009) Antidepressants and the placebo response. Epidemiol Psichiatr Soc 18:318-322. Medline

Lapierre JL, Kosenko PO, Lyamin OI, Kodama T, Mukhametov LM, Siegel JM (2007) Cortical acetylcholine release is lateralized during asymmetrical slow-wave sleep in northern fur seals. J Neurosci 27:11999-12006. CrossRef Medline

Lyamin OI, Mukhametov LM (1998) Organization of sleep in the northern fur seal. In: The northern fur seal. Systematic, morphology, ecology, behavior (Sokolov VE, Aristov AA, Lisitzjna TU, eds), pp 280-302 (in Russian). Moscow: Nauka.

Lyamin OI, Oleksenko AI, Polyakova IG, Mukhametov LM (1996) Paradoxical sleep in northern fur seals in water and on land. J Sleep Res 5 [Suppl 1]:130.

Lyamin OI, Mukhametov LM, Siegel JM (2004) Relationship between sleep and eye state in Cetaceans and Pinnipeds. Arch Ital Biol 142:557-568. Medline

Lyamin OI, Lapierre JL, Kosenko PO, Mukhametov LM, Siegel JM (2008a) Electroencephalogram asymmetry and spectral power during sleep in the northern fur seal. J Sleep Res 17:154-165. CrossRef Medline

Lyamin OI, Manger PR, Ridgway SH, Mukhametov LM, Siegel JM (2008b) Cetacean sleep: An unusual form of mammalian sleep. Neurosci Biobehav Rev 32:1451-1484. CrossRef Medline

Mahowald MW, Schenck CH (2005) Insights from studying human sleep disorders. Nature 437:1279-1285. CrossRef Medline

Marrosu F, Portas C, Mascia MS, Casu MA, Fà M, Giagheddu M, Imperato A, Gessa GL (1995) Microdialysis measurement of cortical and hippocampal acetylcholine release during sleep-wake cycle in freely moving cats. Brain Res 671:329-332. CrossRef Medline

Martin-Cora FJ, Fornal CA, Jacobs BL (2005) Single-unit responses of serotonergic medullary raphe neurons to cardiovascular challenges in freely moving cats. Eur J Neurosci 22:3195-3204. CrossRef Medline

McGinty DJ, Harper RM (1976) Dorsal raphe neurons: Depression of firing during sleep in cats. Brain Res 101:569-575. CrossRef Medline

Monti JM (2011) Serotonin control of sleep-wake behavior. Sleep Med Rev 15:269-281. CrossRef Medline

O'Hearn E, Molliver ME (1984) Organization of raphe-cortical projections in rat: a quantitative retrograde study. Brain Res Bull 13:709-726. CrossRef Medline

Pigott HE, Leventhal AM, Alter GS, Boren JJ (2010) Efficacy and effectiveness of antidepressants: current status of research. Psychother Psychosom 79:267-279. CrossRef Medline

Puizillout JJ, Gaudin-Chazal G, Sayadi A, Vigier D (1981) Serotoninergic mechanisms and sleep. J Physiol (Paris) 77:415-424. Medline

Rinaldi P, Sutko M, Mahnke JH, Verzeano M (1975) Serotonin in the lateral geniculate. Physiol Behav 14:95-102. CrossRef Medline

Ross CA, Trulson ME, Jacobs BL (1976) Depletion of brain serotonin following intraventricular 5,7-dihydroxytryptamine fails to disrupt sleep in the cat. Brain Res 114:517-523. CrossRef Medline

Siegel JM (2009) Sleep viewed as a state of adaptive inactivity. Nat Rev Neurosci 10:747-753. CrossRef Medline

Siegel JM, Rogawski MA (1988) A function for REM sleep: regulation of 
noradrenergic receptor sensitivity. Brain Res Rev 13:213-233. CrossRef Medline

Siegel JM, Nienhuis R, Fahringer HM, Paul R, Shiromani P, Dement WC, Mignot E, Chiu C (1991) Neuronal activity in narcolepsy: identification of cataplexy related cells in the medial medulla. Science 252:1315-1318. CrossRef Medline

Simon RP, Gershon MD, Brooks DC (1973) The role of the raphe nuclei in the regulation of ponto-geniculo-occipital wave activity. Brain Res 58: 313-330. CrossRef Medline

Supin AY, Popov VV, Massa AM (2001) The sensory physiology of aquatic mammals. Boston: Kluwer Academic.

Tarpley RJ, Ridgway SH (1994) Corpus callosum size in delphinid cetaceans. Brain Behav Evol 44:156-165. CrossRef Medline

Ursin R, Bjorvatn B, Sommerfelt L, Underland G (1989) Increased waking as well as increased synchronization following administration of selective 5-HT uptake inhibitors to rats. Behav Brain Res 34:117-130. CrossRef Medline van der Kooy D, Hattori T (1980) Bilaterally situated dorsal raphe cell bodies have only unilateral forebrain projections in rat. Brain Res 192:550-554. CrossRef Medline

Veasey SC, Fornal CA, Metzler CW, Jacobs BL (1997) Single-unit responses of serotonergic dorsal raphe neurons to specific motor challenges in freely moving cats. Neuroscience 79:161-169. CrossRef Medline

Wu MF, Gulyani SA, Yau E, Mignot E, Phan B, Siegel JM (1999) Locus coeruleus neurons: cessation of activity during cataplexy. Neuroscience 91:1389-1399. CrossRef Medline

Wu MF, John J, Boehmer LN, Yau D, Nguyen GB, Siegel JM (2004) Activity of dorsal raphe cells across the sleep-waking cycle and during cataplexy in narcoleptic dogs. J Physiol 554:202-215. CrossRef Medline

Wyatt RJ, Engelman K, Kupfer DJ, Scott J, Sjoerdsma A, Snyder F (1969) Effects of para-chlorophenylalanine on sleep in man. Electroencephalogr Clin Neurophysiol 27:529-532. CrossRef Medline 